\title{
Influence of powder parameters on powder bed and productivity of l-pbf
}

\author{
Johannes Schrage ${ }^{1}$, Johannes Henrich Schleifenbaum ${ }^{1}$ \\ 1 Fraunhofer Institute for Laser Technology (ILT), Germany
}

\begin{abstract}
While L-PBF offers advantages in terms of geometrical freedom or lightweight construction, its use is often limited by economic constraints or currently achievable part costs. With an anticipated increase of L-PBF machine productivity during the next years, an increase of the share of material costs and the share of non-productive time for powder layer application process is to be expected. This results in a demand for less expensive powder materials and advanced processing strategies for the short-and medium-term advancement of L-PBF. As one possible approach, the processing of gas- and water atomized stainless steel (316L) powders with different morphology and particle size distribution as well as their impact on L-PBF productivity is investigated. The actual powder applicability in L-PBF systems and the L-PBF processability determines the minimum necessary powder quality. The main focus of the presented work is put on the interaction between powder quality, powder layer properties, part quality and cost-effectiveness of the L-PBF process. To this end, the influence of the gas and water-atomized powder properties (particle size and morphology) during the powder layer application process at highest possible powder recoater speeds and the resulting powder bed properties (powder layer density, powder bed density, powder demixing) and part properties (part density and tensile strength) is investigated.
\end{abstract}

\section{Keywords}

Additive Manufacturing, Laser Powder Bed Fusion, L-PBF, powder recoating, powder layer, powder bed, properties, powder quality, productivity

\section{Introduction}

At the present time, spherical powders of a certain particle size distribution generated via gas atomization are used for the L-PBF process. Due to its manufacturing route, these powders are expensive to produce. By comparison, in 2015 water-atomized powders can be produced much more cost-effectively, by an estimated factor in the range from 5 to 10 but with lower powder quality. The powder quality can be described with the powder properties such as the particle morphology (spherical vs. spattered particle shape) or the powder tap density. The powder production method has a decisive influence on the powder properties and thus on the powder applicability in L-PBF systems. [1,2]

The aim of the investigations is to illustrate the relationship between the powder particle properties (particle sizes and morphology) resulting from different powder production processes on the powder properties (powder layer density) and on the component quality (part density, surface roughness) and component costs. The presented work is mainly focused on the interaction between the powder particle properties resulting from different powder production 
processes, the powder application parameters and the resulting powder bed properties and part properties in the Laser Powder Bed Fusion (L-PBF) process.

\section{Methodology}

The investigations are carried out using different sized powder fractions produced by means of gas and water atomization. The two powder batches are subdivided into five fractions via sieving processes. For the examinations a fine (mesh size $25 \mu \mathrm{m}-37 \mu \mathrm{m}$ ) and a coarse (mesh size $53 \mu \mathrm{m}-74 \mu \mathrm{m}$ ) powder batch of each powder manufacturing route is used. The powders are applied at different powder recoater speeds both in powder application test bench without any L-PBF process and with the same powder recoating parameters inside an L-PBF laboratory machine with a real L-PBF process.

\subsection{Powder bed analysis}

The powder application tests are carried out on a specially developed test bench. It is equipped with a powder recoater tool, a laser line scanner, a load cell and a SLR camera (see Fig. 1).

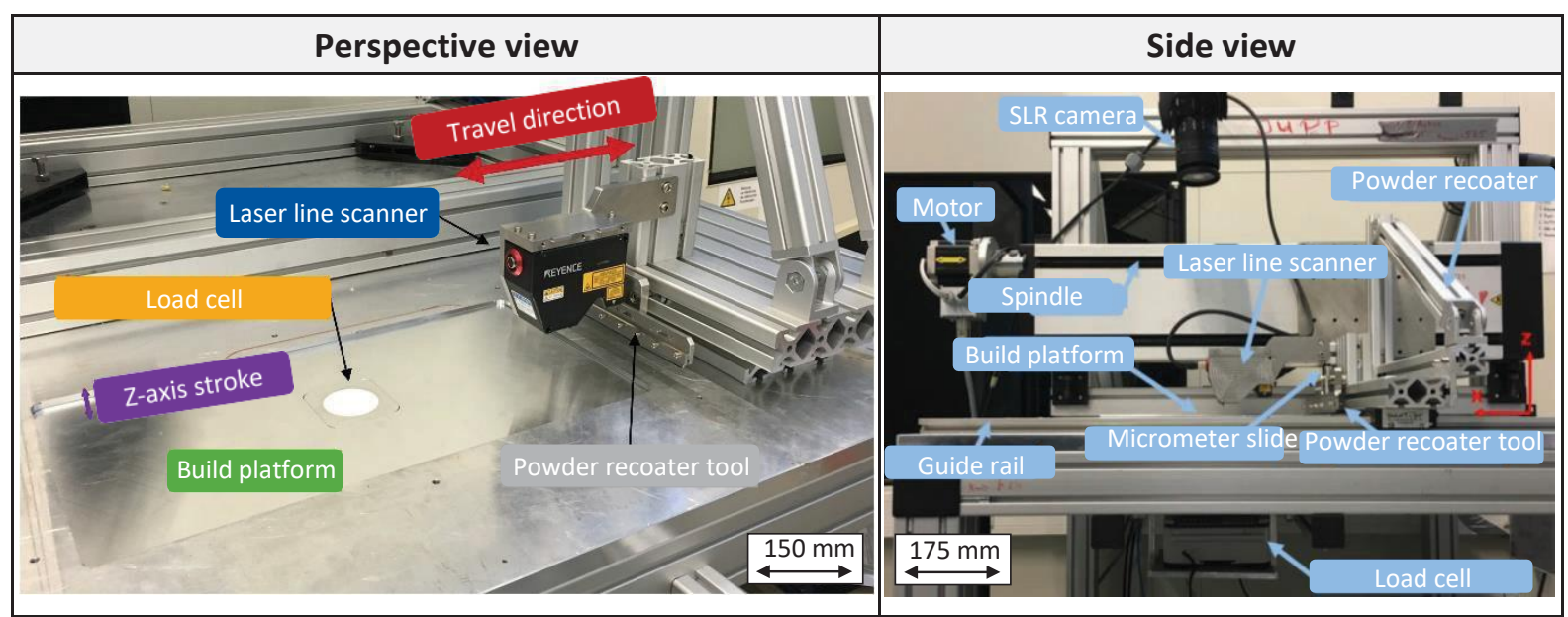

Fig. 1: Photographs of the powder application test stand in perspective view and in a side view

For the qualitative assessment of the powder layer quality, a photographic visual comparison of applied powder layers is carried out. The powder layer translucency is an indicator of the powder layer density, which can be estimated by the visibility of the underlying substrate plate.

In order to evaluate the suitability of the above-mentioned methods to assess the processability of these powders in L-PBF machines, the investigations are expanded by powder processing and application under real conditions. Liu et al. [1] manufactured a hollow container by L-PBF and weighed the involved powder after the whole build job in order to determine the powder mass, respectively density inside the powder bed. For measuring the powder bed density in each deposited powder layer a measuring methodology and set-up is developed that is implementable inside L-PBF systems and processes. For the quantitative determination of the powder layer density a defined quantity of powder is applied in a powder layer thickness $D_{S}$ of 
$0.06 \mathrm{~mm}$ by means of the powder recoating tool. The excess powder, which does not remain on the building platform, is conveyed into the powder overflow. The applied powder layer surface is measured by means of a laser line scanner and in this way the actual layer thickness is determined. The mass of the powder layer applied can be determined by the load cell integrated in the test bench and the powder layer density can thus be calculated. The powder layer density is determined as the mean value of six powder layers.

In order to describe the powder application behavior quantitatively, the demixing of the powder particles is investigated. Demixing is defined as a local redistribution of powder particles of different sizes along the powder application direction. The powder samples are extracted from the powder storage, from the powder bed and from the powder overflow. These powder samples are examined with regard to the powder particle size distribution using the analytical instrument CAMSIZER ${ }^{\circledR}$ X2 by Retsch Technology $\mathrm{GmbH}$. With an optical measurement and automatic software evaluation of a powder sample, particle morphology characteristics of the individual powder fractions like the particle circularity, convexity and elongation can be measured simultaneously. The particle size distribution is typically plotted in a so called the sum distribution plot. The percentage volume fraction $\mathrm{X}$ of the particles contained in particles smaller than $d_{x}$ is plotted over the particle size $d_{x}$. To characterize a particle size distribution the values $d_{10}, d_{s o}$ and $d_{90}$ are used. The value of $d_{s o}$ is defined as the mean particle size [3].

\section{$2.2 \quad$ L-PBF processing}

The powder properties, the powder application parameters and the L-PBF process parameters used are shown in Fig. 2. The L-PBF build job includes cube test samples (designated W1 to W5 in Fig. 3 down left), round samples (designated Z1 to Z6) and hollow samples (designated $\mathrm{H} 1$ to $\mathrm{H} 4$ ), which are used to determine the part density, the mechanical characteristics (tensile strength $R_{m}$, yield strength $R_{p 0.2}$ and elongation $A$ ) and the powder bed density. The mechanical characteristics are determined by tensile tests on test specimens in "as built" condition without mechanical post-processing and without heat treatment. The test specimens are manufactured using L-PBF process parameters shown in the table on the right, which allows the manufacturing of parts with a density greater than $99.5 \%$. [2] The photograph on the bottom right shows exemplary an L-PBF manufactured build job with the mentioned test specimen which is manufactured on an L-PBF laboratory machine. 


\begin{tabular}{|l|c|c|c|c|}
\hline \multicolumn{4}{|c|}{ Powder and powder recoating parameters } \\
\hline Material & \multicolumn{4}{|c|}{$1.4404 / 316 \mathrm{~L}$} \\
\hline $\begin{array}{l}\text { Atomization } \\
\text { medium }\end{array}$ & Water & Water & Gas & Gas \\
\hline $\begin{array}{l}\text { Particle size } \\
{[\mu \mathrm{m}]}\end{array}$ & $25-37$ & $53-74$ & $25-37$ & $53-74$ \\
\hline $\begin{array}{l}\text { Tap density } \\
{\left[\mathrm{g} / \mathrm{cm}^{3}\right]}\end{array}$ & 2.89 & 3.29 & 4.57 & 4.67 \\
\hline $\begin{array}{l}\text { Powder recoater } \\
\text { speed }\end{array}$ & \multicolumn{5}{|c|}{$50 \mathrm{~mm} / \mathrm{s} ; 100 \mathrm{~mm} / \mathrm{s}$} \\
\hline
\end{tabular}

\begin{tabular}{|l|l|}
\hline \multicolumn{2}{|c|}{ L-PBF process parameters } \\
\hline Laser power $\mathrm{P}_{\mathrm{L}}$ & $250 \mathrm{~W}$ \\
\hline Scan speed $\mathrm{v}_{\text {Scan }}$ & $800 \mathrm{~mm} / \mathrm{s}$ \\
\hline Laser beam diameter $\mathrm{d}_{\mathrm{S}}$ & $0.08 \mathrm{~mm}$ \\
\hline Hatch distance $\mathrm{t}: \mathrm{y}_{\mathrm{S}}$ & $0.1 \mathrm{~mm}$ \\
\hline Layer thickness $\mathrm{D}_{\mathrm{S}}$ & $0.06 \mathrm{~mm}$ \\
\hline Scan vector length $\mathrm{L}$ & $5 \mathrm{~mm}$ \\
\hline Volume energy $\mathrm{E}_{\mathrm{V}}$ & $52.08 \mathrm{~J} / \mathrm{mm}^{3}$ \\
\hline
\end{tabular}
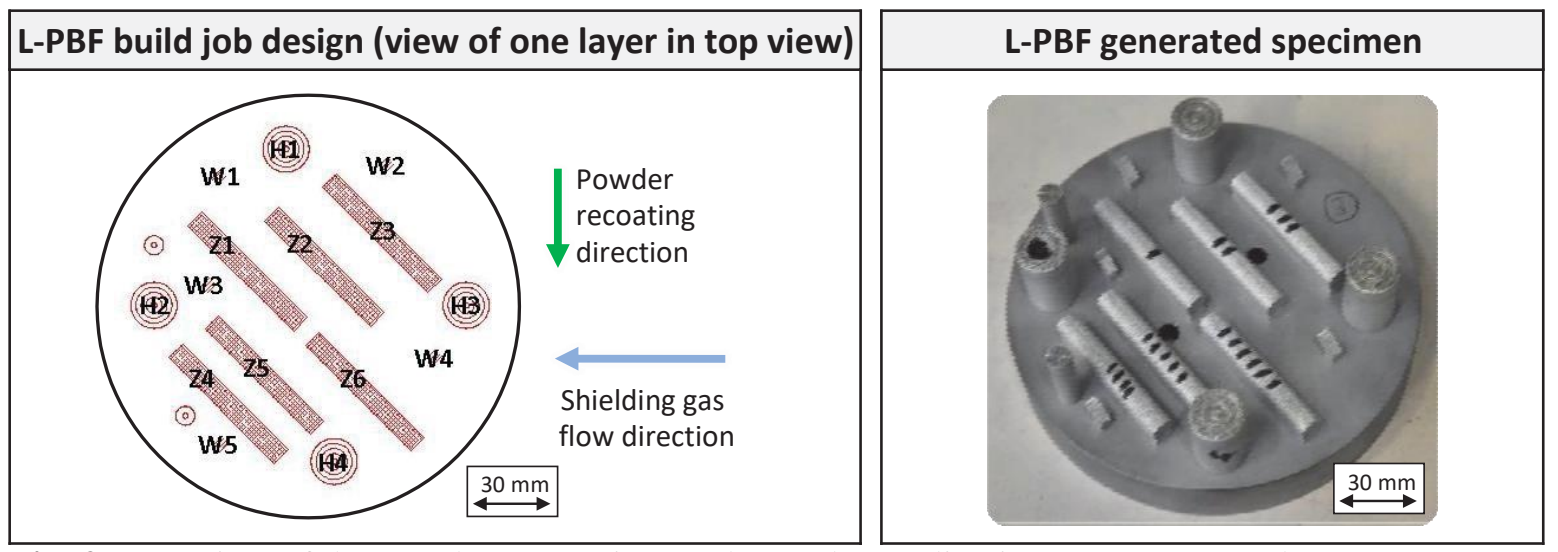

Fig. 2: Overview of the powder properties used, powder application parameters and L-PBF process parameters and the arrangement of the test specimens in the L-PBF construction job

\section{Results}

\subsection{Powder bed density}

Fig. 3 shows photographs of powder layers of different powders, applied with different powder recoating tools. The powder bed density and homogeneity of the powder application is influenced by the powder recoating tool used, such as the blade, brush or lip. The powder bed surface generated by the recoating of a water atomized powder with a spattered grain shape tends to be more inhomogeneous with a simultaneously lower powder bed density. The use of a blade tends to produce homogeneous layers. When a brush is used, grooves are created in the powder bed. If a lip is used for powder application, a waviness is created in the powder bed. Possible reasons for these resulting properties may be different friction effects between the powder particles and the powder recoating tool. Larger powder particles may get caught in the brush bristles and lead to the stripes. If the lip is used, the larger powder particles may be released unevenly along the powder application path. 


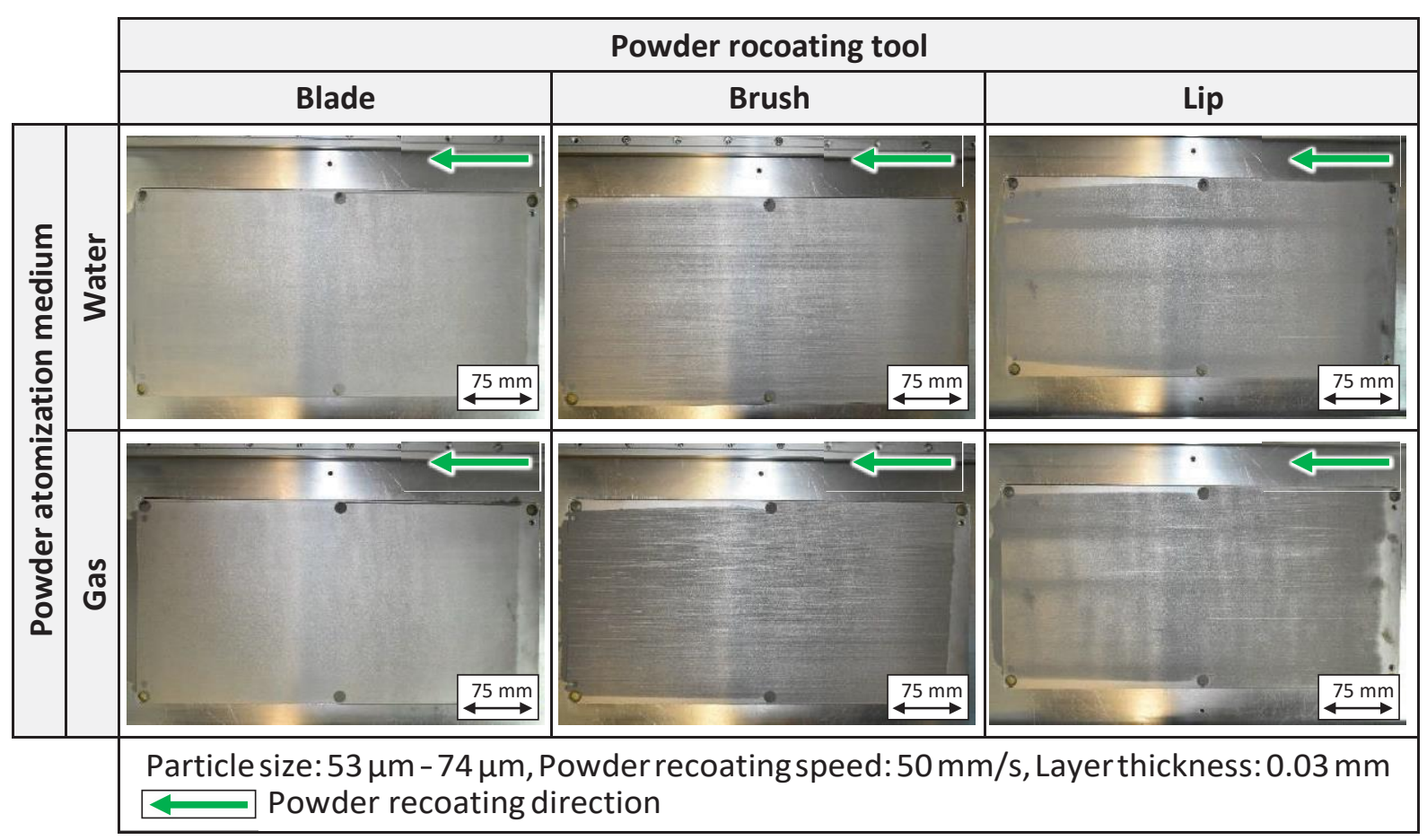

Fig. 3: Photographs of powder layers, applied with different powder recoating tools

Fig. 4 shows the measured powder layer density of powder layers out of powders from different atomization routes and from different powder coating conditions (with and without LPBF process). The higher the speed of the powder recoater movement during powder application, the lower the resulting powder bed density (see D4.1). The influence of the powder recoater speed on the powder bed density is greater for water atomized powder than for gas atomized powder (see D4.1 and D4.2). This suggests an influence of particle shape or powder flowability on the powder bed density.

The smaller the chosen layer thickness in proportion to the powder particle size distribution (in this case $D s=0.03 \mathrm{~mm}$ in proportion to particle sizes in the range from $53 \mu \mathrm{m}$ to $74 \mu \mathrm{m}$ ), the lower the powder bed density (see Fig. 3). Large powder particles are captured by the powder recoating tool and transported into the powder overflow. The fine portion of the powder remains in the powder bed. This results in demixing of the powder during the L-PBF process (see section 3.2). 


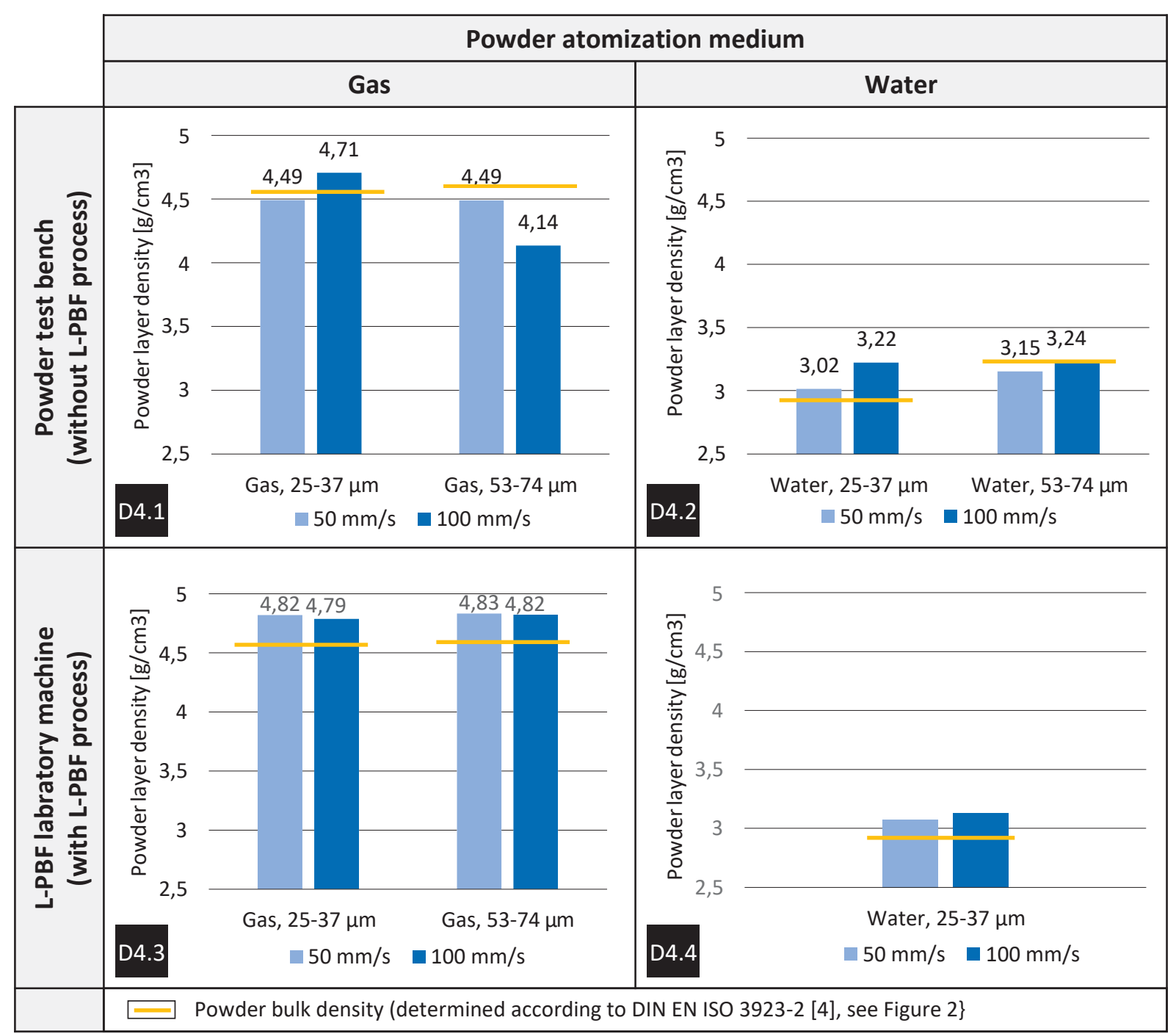

Fig. 4: Diagrams showing the powder layer density as a function of the type of powder atomization, the powder particle sizes and the powder recoater speed

The essential findings from the analysis of the powder bed density are that the powder layer densities determined on the basis of the powder application tests correspond to the values according to standardized procedures (compare Fig. 4 and Fig. 2).

When processing gas atomized powders at high powder recoater speeds it tendentially leads to low powder bed densities compared to the powder bed densities produced at low powder recoater speeds (see D4.1 and D4.3).

When processing water atomized powders at high powder recoater speeds the powder bed densities tend to be higher compared to the powder bed densities produced at low powder recoater speeds (see D4.2 and D4.4).

\subsection{Powder particle demixing}

Fig. 5 shows the results of the powder particle size distribution analysis $\left(d_{90}\right)$ of the individual samples taken from the powder storage, from the powder bed and from the powder overflow. 


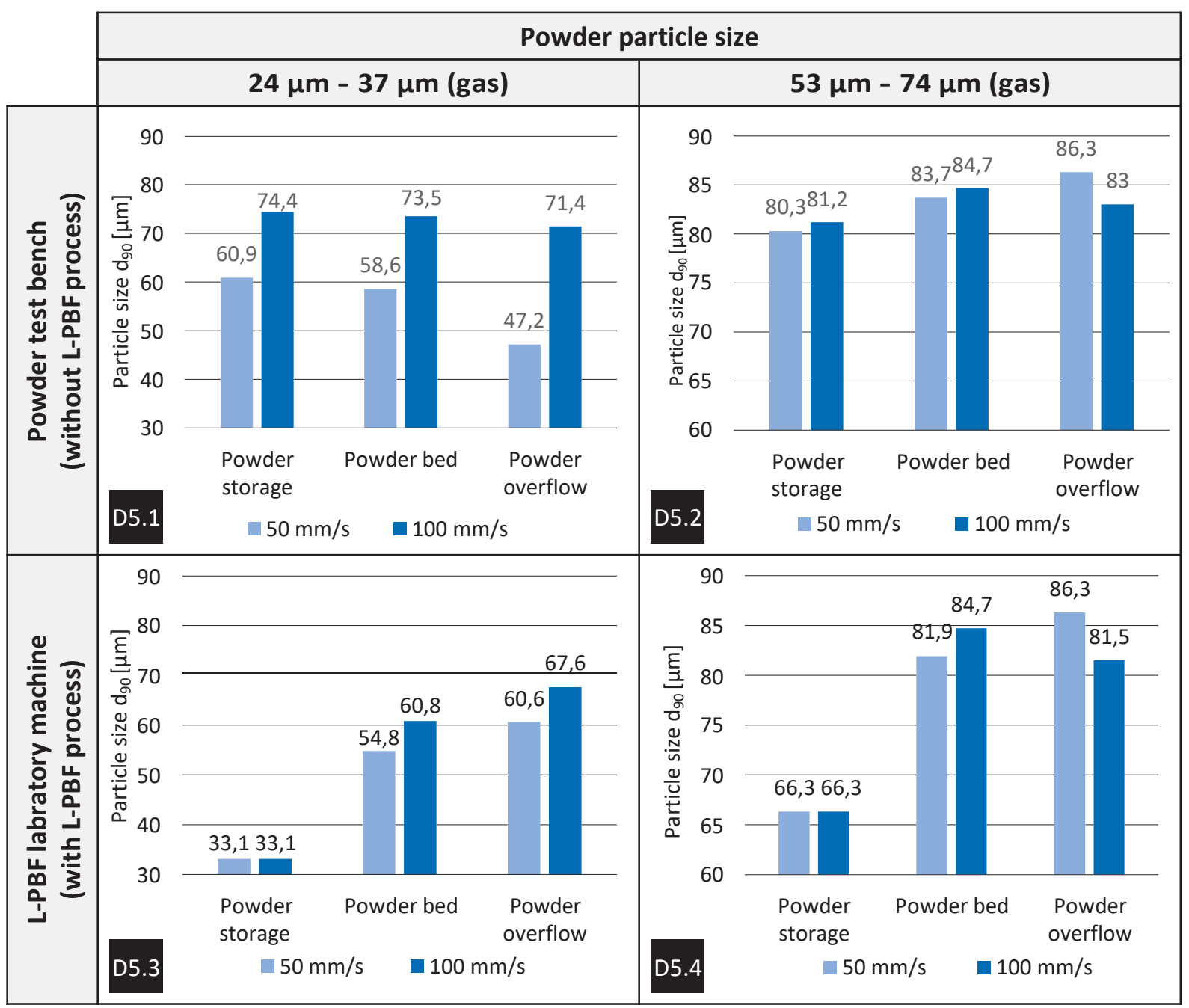

Fig. 5: Diagrams showing the powder particle size distribution of the powder samples depending on the removal position, the powder fraction and the powder recoater speed. As powder recoating tool the silicone lip is used.

An essential result of the segregation analysis is that large powder particles are predominantly transported into the overflow, especially at low powder coater speeds (at $50 \mathrm{~mm} / \mathrm{s}$, see diagrams D5.2, D5.3 and D5.4). This behavior can be confirmed by the larger powder particles (larger $d_{90}$ values) in the powder overflow compared to the powder particles in the powder bed. When increasing the powder recoater speed to $100 \mathrm{~mm} / \mathrm{s}$, the demixing also increases (see D5.1 and D5.3). For the coarse powder fraction (mesh size in the range from $53 \mu \mathrm{m}$ to $74 \mu \mathrm{m}$ ), both without and with L-PBF process applies: At low powder recoater speeds, the large particles are predominantly transported into the powder overflow (see D5.2 and D5.4). At high powder recoater speeds, the large particles remain predominantly within the powder bed (low $d 90$ values in powder overflow, see D5.2 and D5.4).

In L-PBF processing of the fine powder fraction, the powder particle size distribution in the powder overflow increases at both low and high powder recoater speeds, which may indicate increased spatter formation in the process (see D5.3 and D5.4). 


\subsection{Mechanical properties}

The determined mechanical properties of the test specimen such as tensile strength $R_{m}$, yield strength $\mathrm{R}_{\mathrm{p} 0.2}$ and elongation at break A are shown in Fig. 6.

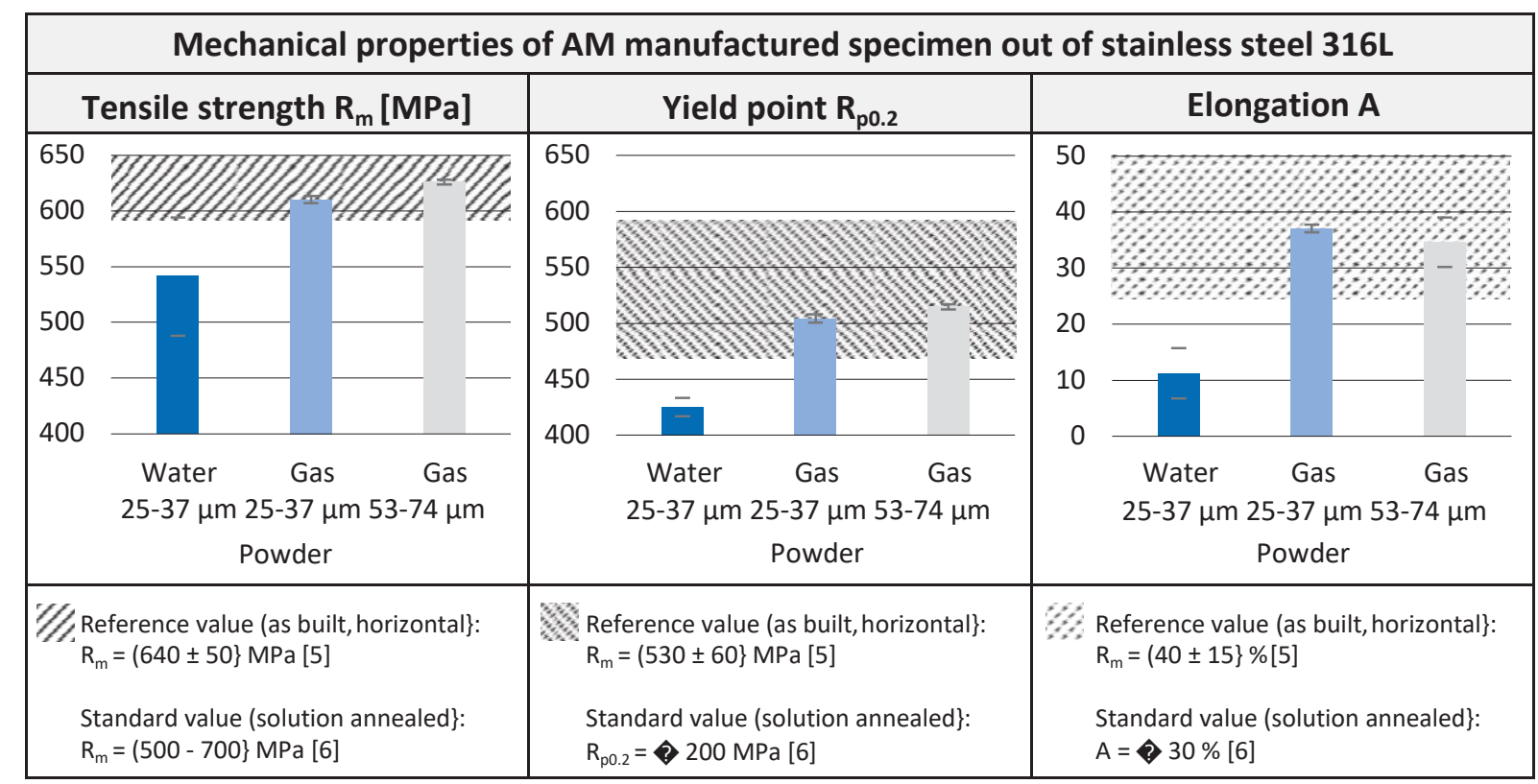

Fig. 6: Diagrams to show the mechanical characteristics of the test specimens

The essential findings are the following: When processing gas atomized powders the tensile strength $R_{m}$ and the yield strength $R_{p 0.2}$ are in the range of the standard values. Furthermore the elongation $\mathrm{A}$ is in the area of the standard value. The measured values also correspond to reference values from the literature.

When processing water atomized powders the tensile strength $R_{m}$ and yield strength $R_{p 0.2}$ are below standard values. Also the elongation $\mathrm{A}$ is below the standard value and below the literature values.

The deviations of the mechanical characteristic values of the water atomized powders can be attributed to the density values between $99.5 \%$ and $99.6 \%$. The density values of the gas atomized powders are $99.8 \%$ to $99.9 \%$. Previous work by Pichler et al has shown that it is possible to process water sprayed powder into components with a density > $99.9 \%$ [2]. Compared to the processing of gas atomized powders, the energy input of water atomized powders is increased by approximately $10 \%$.

In order to reduce the non-productive times for powder application, the investigated coating speeds can be increased from $50 \mathrm{~mm} / \mathrm{s}$ to $100 \mathrm{~mm} / \mathrm{s}$ without any significant loss in quality. Depending on the component geometry to be produced, considerable time savings can be achieved here. The example in Fig. 7 shows the relationship between the powder coater speed (or coating time, respectively) and the laser exposure time. 


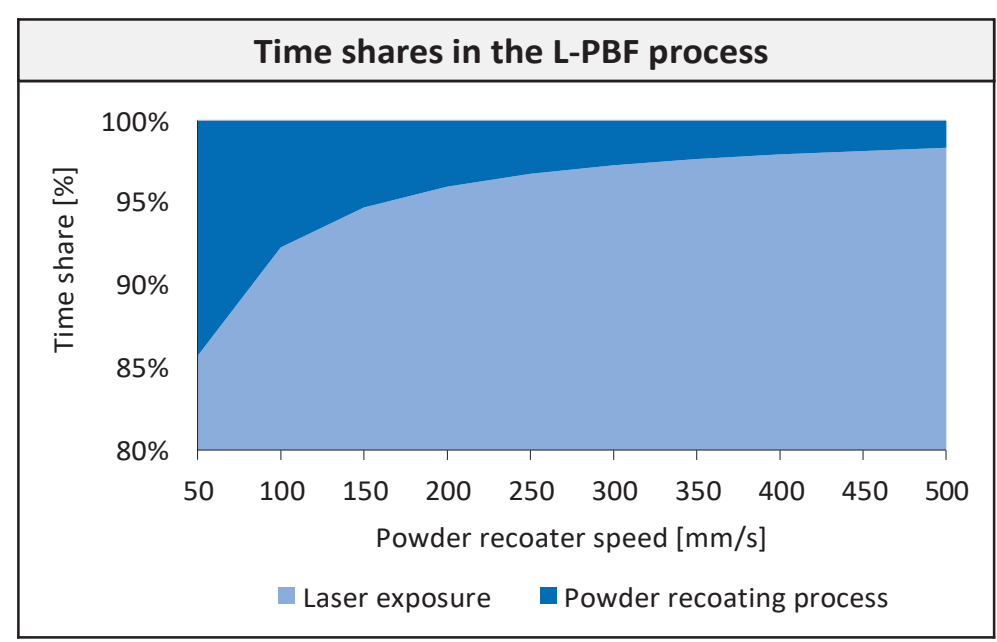

\begin{tabular}{|l|l|}
\hline \multicolumn{2}{|c|}{ L-PBF process parameters } \\
\hline $\begin{array}{l}\text { Laser processing } \\
\text { time per layer } \\
\text { (constant) }\end{array}$ & $120 \mathrm{~s}$ \\
\hline $\begin{array}{l}\text { Powder recoater } \\
\text { travel distance } \\
\text { (constant) }\end{array}$ & $1000 \mathrm{~mm}$ \\
\hline
\end{tabular}

Fig. 7: Diagram to show the time shares of laser exposure and powder recoating process in relation to the powder recoating speed

Assuming a constant laser exposure time of 120 seconds per layer and a travel distance of the powder recoater of $1000 \mathrm{~mm}$, the increase in the powder recoater speed leads to a relative decrease in the total L-PBF build job time share from $14.3 \%$ at $50 \mathrm{~mm} / \mathrm{s}$ powder recoater speed to $1.64 \%$ at $500 \mathrm{~mm} / \mathrm{s}$. With short laser exposure times per layer the advantage of high powder recoater speeds is increased.

\section{Summary and outlook}

Powders from different manufacturing routes, one gas and one water atomized batch were characterized with standardized methods regarding their particle size distribution. Due to their irregular shape the particle size distribution of water atomized powders differs from the spherical shaped gas atomized powders, which directly affects the qualitative powder layer properties. The powder bed density with water atomized powders is lower compared to gas atomized powders. L-PBF processing with reproducible process parameters results in specimens with the desired density of $>99.5 \%$ for all powder types. For both the gas and water atomized powders an increase of powder recoater speed from $50 \mathrm{~mm} / \mathrm{s}$ to $100 \mathrm{~mm} / \mathrm{s}$ allows to process homogeneous and for the L-PBF process suitable powder layers.

By choosing new powder particle size limits the economic efficiency in powder production can be increased. By leaving the fine powder particles inside the batch and only removing the coarse particles which, depending on the thickness of the coating, would be discharged by the powder recoater the share of the powder charge that is used for the L-PBF process is increased. In total the higher yield in powder production in combination with costefficient power production methods like water atomization is estimated to result in a $5 \%$ to $10 \%$ lower powder price and thus lead to a more economical L-PBF production. Adapting processing strategies to the powder properties can reduce porosity due to excessive energy input as well as lack of fusion defects caused by insufficient energy input.

In the further course, the focus will be on the investigation of the powder application over large areas (up to one square meter). In particular, the influence of a significant increase in the powder recoater speed on the powder layer properties (up to one meter per second) on dust generation and on L-PBF process productivity will be investigated. 


\section{Acknowledgements}

This research has been financed by the Germany ministry of Research and Education in the Digital Photonic Production Direct (13N13710) project as part of the "Research Campus Public-Private Partnership for Innovation" initiative.

\section{References}

[1] Gibson, I., Rosen, D. W., and Stucker, B., Additive Manufacturing Technologies:

3D Printing, Rapid Prototyping, and Direct Digital manufacturing, 2nd ed., Springer, New York, 2015, pp. 1-498.

[2] T. Pichler, J. Schrage, J. H. Schleifenbaum: Increasing Productivity of Laser Powder Bed Fusion (L-PBF) by Qualifying and Processing Different Powder Qualities and Application of Intelligent Processing Strategies, Proceedings, Fraunhofer DDMC 2018 Conference, Berlin (2018)

[3] ISO 13320, Particle size analysis - Laser diffraction methods, International Standard Organziation (2009, p. 5)

[4] DIN EN ISO 3923-2, Metallic powders - Determination of apparent density - Part 2: Scott volumeter method (1987)

[5] EOS GmbH, Material data sheet - EOS Stainless Steel 316L, Website (2014), URL: https://www.eos.info/material-m/download/material-datasheet-stainlesssteel-3161.pdf, Internet access: $17^{\text {th }}$ June 2019

[6] Deutsche Edelstahlwerke GmbH, Technical Data Sheet - 1.4404, Website (2014), URL: https://www.dew-stahl.com/fileadmin/files/dew-stahl.com/documents/Publikationen/ Werkstoffdatenblaetter/RSH/1.4404_en.pdf, Internet access: 17 ${ }^{\text {th }}$ June 2019 